\title{
From Numerical Calculations to Materials Testing Homologation: A Biaxial Fatigue Reliability Prediction Methodology for Structural Components
}

\author{
Daniel Muller Spinelli*, Caio de Carvalho Scozzafave, Dirceu Spinelli, Waldek Wladimir Bose Filho \\ Materials Engineering Department, University of Sao Paulo - USP, \\ Av. Trabalhador Saocarlense, 400, CEP 13566-590, Sao Carlos, SP, Brazil
}

Received: September 25, 2012; Revised: April 19, 2013

\begin{abstract}
This article investigates a fatigue approach conducted from the design phase to testing approval. It considerers modern analytical and experimental tools for structural durability assessment over each development phase for two reference components aiming an early approval methodology validation for a new design. A Finite element analysis procedure was used to set critical spots for measurements minimizing the data acquisition efforts. Based on measured data, strain life calculation was done for two reference components in order to set the release goals for a new design submitted to this approach. An innovative fatigue experimental technique is proposed using component extracted specimens and an edited input cycle loads. Considering the random data from a standard test track and signal proportionality evaluation, while assuming the Brown Miller equation for bi-axial fatigue together with Ramberg-Osgood model, equivalent damage load blocks were edited and used as input for durability assessment on specimens representing the component material. The results for the three parts materials were plotted as Weibull diagram for B10 life estimation. Fatigue life results showed good correlation with the reference parts structural performance thus validating the method as well as approving the new design for production without additional on-vehicle durability testing. The methodology and the fatigue testing proposal is therefore recommended for future applications on similar developments.
\end{abstract}

Keywords: automotive components/engineering, product development, life prediction, fatigue test methods, biaxial stress

\section{Introduction}

Structural components development has been accelerated in the past twenty years by using computer simulation tools and fatigue life prediction approaches ${ }^{1}$. However, test acceptance criteria are still conducted on manufactured components subjected to a specific service condition or with an accelerated testing program conducted on a full test bench for final structural integrity homologation.

Engineers have used several simplifications to compensate for the uncertainties with safety factors on the design phase to overcome the complexity of conducting sophisticated analysis and experiments that are rarely usable during a high pressure environment for product development. Whenever possible it is imperative to search for alternatives that consider consolidated uniaxial fatigue models ${ }^{2}$.

Fatigue cracks are mostly initiated on components surface where plane stress fatigue methods can be adopted ${ }^{4}$. Therefore, significant efforts on mathematical modeling development have been made considering the bi-axial damage behavior ${ }^{3}$. Multiaxial stress environment can be proportional or non-proportional even under uniaxial loads due to geometry constrains at notches ${ }^{5}$. Non proportional stresses require often the critical plane approach ${ }^{1}$ and range acceptance criteria can be used to simplify the analysis scope for proportional loading ${ }^{3}$

*e-mail: daniel.spinelli@uol.com.br
A simplified approach would be the generation of an equivalent load histogram from a multidirectional stress field that could be handled by the well established uniaxial fatigue models ${ }^{6}$. The local strain approach is the most indicated for durability prediction by fatigue damage calculations in the automotive industry ${ }^{7}$. Therefore, a model for a reliable equivalent strain data is required for calculating the component total life expectancy.

The success of a multiaxial fatigue prediction is directly influenced by the ability to acquire accurate strain time histories ${ }^{1}$. Efforts must be made to the critical stress regions for detailed and precise investigation, instead of a generalized fatigue approach. Thus, discovering the high stress positions on a given component is a must for setting the strain gages over the critical locations.

Other important modeling aspect is the component material properties. The determination of cyclic fatigue properties of the final manufactured parts enable the use of realistic parameters considering the hardening effects caused by the production process ${ }^{8}$.

For final structural homologation purpose, manipulation methods for accelerate tests results considers 1) Associated to a cycle testing frequency increase up to the resonance limit, the actual praxis includes manipulation of input data by ignoring the low range cycles below $15 \%$ of the maximum load 9 , 2) building up a cumulative distribution 
from a time-history rainflow ${ }^{10}$ or 3 ) filtering the measured events with calculated stresses below $50 \%$ of the material fatigue limit ${ }^{8}$. A successful technique was proposed using the strain amplitude together with the Smith-Watson-Topper fatigue model $^{11}$ for editing the cycles with the highest associated damage ${ }^{12}$ reducing considerably the signal length considerably and consequently the time to run a complete test program.

Nevertheless, sophisticated testing facilities are necessary for simulating complex mechanical system often found in road vehicles, under a multiaxial loading environment. A simplification considering the fatigue phenomena localized to the component material region subjected to the measured strain environment showed to be promising for accessing the required experimental results for final development release.

This paper describes a methodology proposal and mathematical modeling for setting a new development approach using the bi-axial fatigue theory and realistic component material properties for damage calculation as well as creating an uniaxial equivalent signal from a complex plane strain measurements to be used as input for a specimen fatigue testing under variable loading condition. Three designs are considered for evaluation, two of them are existing ones with reference structural performance data available and a third new development which has followed the proposed technique.

\section{Methodology}

The development goal is to create a new suspension component (NSC), based on the structural performance of an existing part used in severe application (SSC), which could be interchangeable with another existing design currently used in a lighter application (LSC) with time and costs restrictions.

A new method for developing structural components was created for accomplishing the time and costs constrains using more engineering analysis rather that extensive onroad testing procedures. From numerical simulation to component material testing, this work concentrates the efforts on data manipulation and critical approach to set the maturity risks for the new design as a pilot to be further used in similar development cases.

The project scope follows the main deliverables workflow for accomplishing the full development program as presented in Figure 1. First a theoretical stress analysis using the Finite Element Method was done for searching the critical regions that will guide the strain-gages positions. Than, measurements over a reference test track was accomplished and subsequently signal analysis conducted for checking data statistics and proportionality. The materials fatigue properties were later obtained from specimens of manufactured parts using the E606-04 procedure $^{13}$. The fatigue damage model calculation was done considering the rainflow cycle counting technique, Brown-Miller and Ramberg-Osgood equations ${ }^{4}$ associated with principal strain from the measured data, and the Palmgren-Miner ${ }^{4}$ method for cumulative damage results. At this point, an equivalent strain signal was generated by extracting the rainflow cycles that actually cause damage, which was transformed in a load input signal using the Ramber-Osgood model, enabling a load controlled material durability experiment. Finally, material specimens from the three manufactured components were tested and the results plotted in a Weibull diagram ${ }^{14}$, which were than compared with actual field data from the two reference parts.

\section{Finite Element Analyisis}

The Finite Element Method (FEM) is a well known engineering tool for predicting the structural stresses of a component geometry subjected to loads and guided by constrains. This analytical method divides the continuum in small elements, linked by nodes, that represents the elastic equations for determining the node displacements and the material properties for calculating the corresponding stresses at each element position.

The three components under investigation are different rear axle carriers commonly used in commercial vehicles air suspension type. The Figure 2 shows the FEM results for the (a) SSC Design, (b) LSC Design, (c) NSC Design considering an impulse load case of $2,5 \mathrm{G}$ vertical acceleration downwards over the whole vehicle mass considering the rear axle carrying $13 \mathrm{t}$ payload (1,7 t unsprung mass plus 11,3 $\mathrm{t}$ sprung mass).

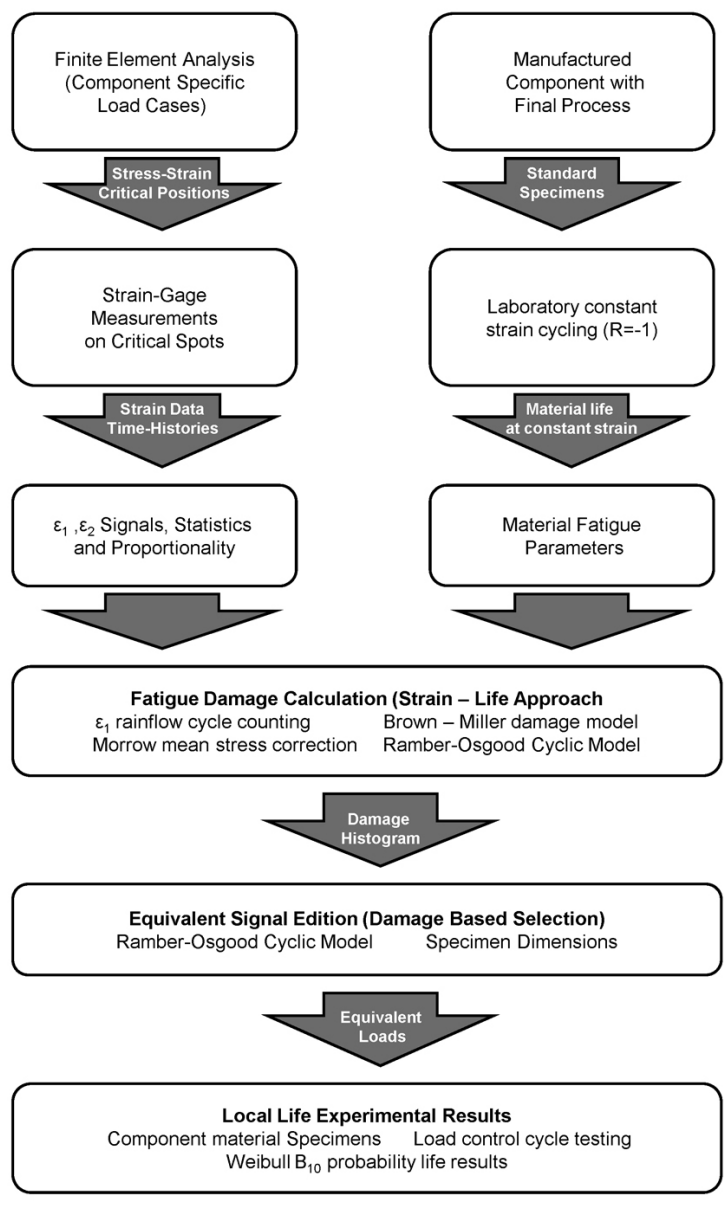

Figure 1. Proposed methodology workflow. 
The results are presented as percentage value based on the material yield strength criteria - $\mathrm{Se}(0,2 \%)$ - as specified for SSC - E380TM, LSC - St52 and a new proposed material for NSC - LNE700. The LSC design presented stresses above the criteria in a bigger area forecasting plastic deformation during service loads. The NSC design presented the level and contour plots below criteria as the benchmark values from SSC design.

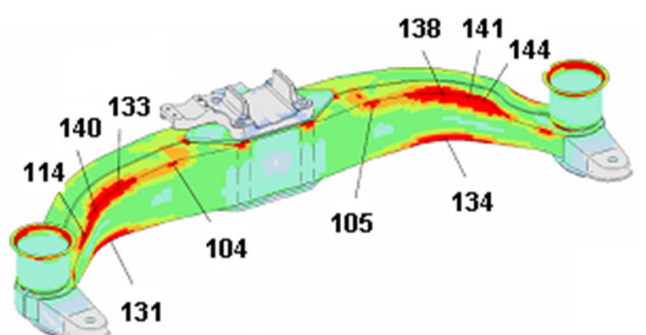

(a) SSC Design

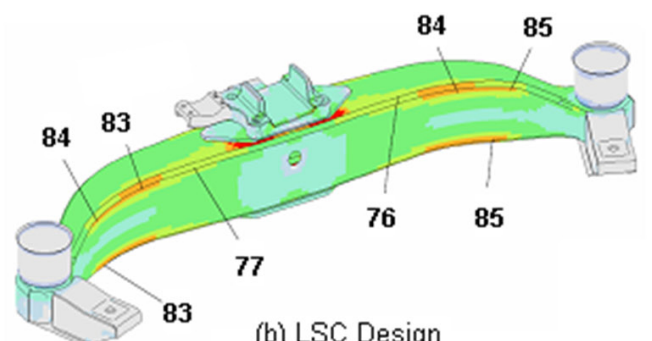

(b) LSC Design

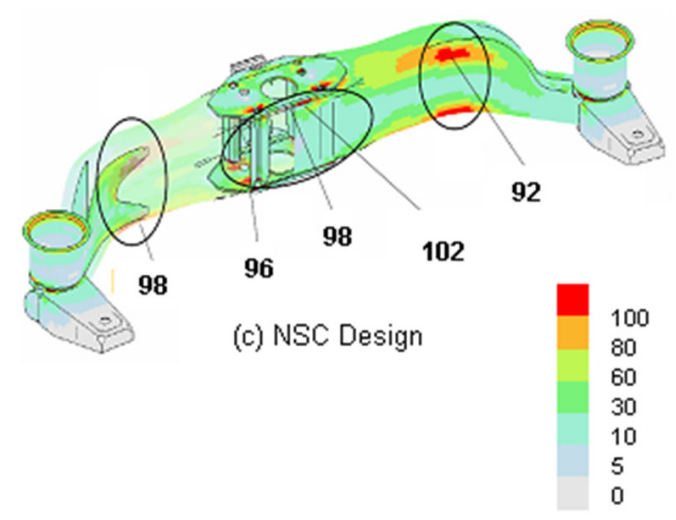

\begin{tabular}{ccccc} 
& & E380TM & St52 & LNE700 \\
\hline Su & {$[\mathrm{MPa}]$} & 541 & 428 & 766 \\
$\mathrm{Se}(0,2 \%)$ & {$[\mathrm{MPa}]$} & 454 & 324 & 430 \\
\hline
\end{tabular}

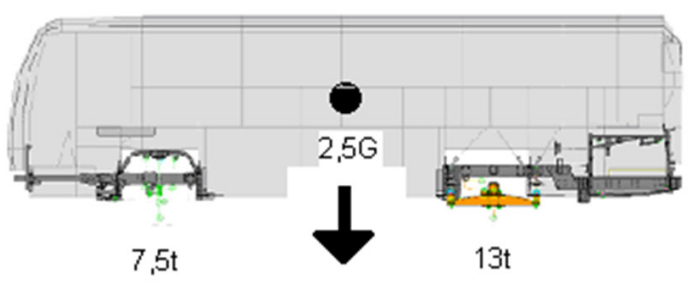

Figure 2. FEM results for the three designs as percentage of the respective material yield strength.
From this static analysis it was possible to define the critical areas which were assumed as been the strain-gages position for time-history measurements and refined fatigue analysis. At this maturity level, it is possible to conclude that the new design complies theoretically with the reference SSC design in a quasi-static environment.

\section{Strain Mesurements and Signal Analysis}

Based on the FEA results, the existing SSC design and LSC design were instrumented, assembled and measured on a vehicle for one lap over a standardized test track, while the NSC design prototype was waiting for the tool manufacturing which was released after decision based on the structural benchmark correlation for the peak measured stresses and the FEM static stress results from previous analysis. Next, the experimental procedure was conducted for strain time-history acquisition in a similar procedure on the NSC design prototypes parts.

The strain-gages were positioned following the FEM critical spots for measurements and the acquired timehistories for $\varepsilon_{\mathrm{x}}, \varepsilon_{\mathrm{y}}$ and $\varepsilon_{45}$ were transformed into principal strains. The LSC design data required further manipulation due to some local plastic deformation and the residual strains were eliminated by subtracting the deformation value from the original signals. The measurement points with biggest RMS values were assumed to be detailed for its proportionality. The signals proportionality were calculated by Equation 1 and are presented in Figure 3 for (a) SSC design, (b) LSC design, (c) NSC design.

Most of the measured time-histories lays within the $10^{\circ}$ proportional range, with exception of the NSC design point R5. Therefore for the critical evaluation points, the results precision would be minor affected in $2 \%$ for a fatigue analysis considering the Brown-Miller model ${ }^{3}$.

$$
\phi=\frac{1}{2} \arctan \left(\frac{2 \varepsilon_{45}-\varepsilon_{x}-\varepsilon_{y}}{\varepsilon_{x}-\varepsilon_{y}}\right)
$$

\section{Materials Data}

Precise materials data are important for fatigue life calculation. Whenever possible, a manufactured material sample shall be used for determinate the real properties. Therefore, extraction of specimen directly from the components would inherit the manufacturing effects on the microstructure and give more accurate cyclic fatigue parameters to be used furthermore on the life prediction model. The Figure 4 shows how specimens were removed, as well as their size and geometry.

The material strength and fatigue properties for the three steel types are presented in Table 1 and were obtained following the ASTM E606 - 04 standard $^{13}$, in total strain control using from 0,5 up to $3 \mathrm{~Hz}$ cycling frequency.

The strain-life curves were plotted together in Figure 5 using the Coffin-Manson Equation $2^{4}$. The results demonstrate higher low-cycle fatigue performance for the LNE700 steel while for high cycle fatigue it is very close to the E380TM. The St52 presented the weakest fatigue performance from all. 
(a) SSC Design

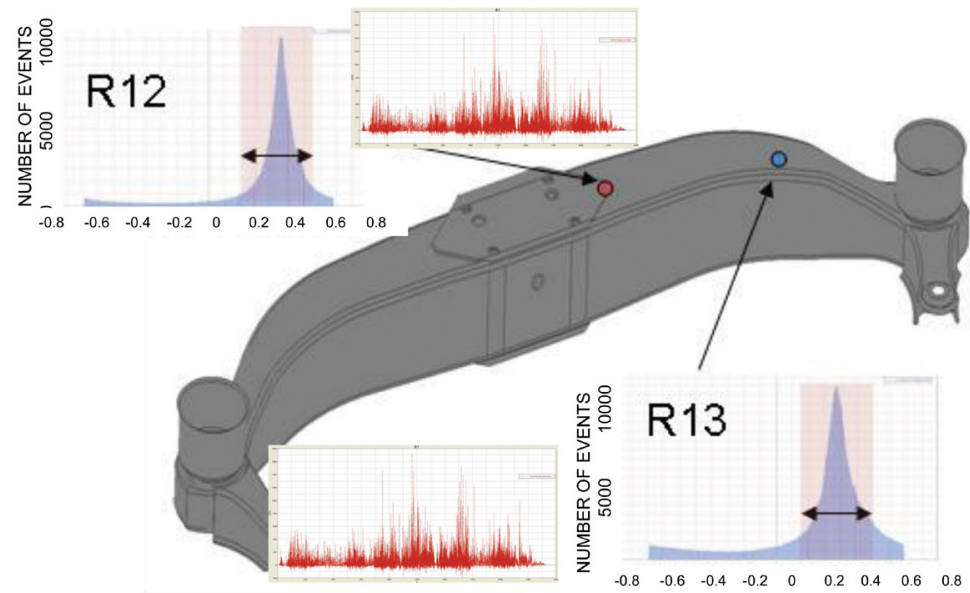

(b) LSC Design

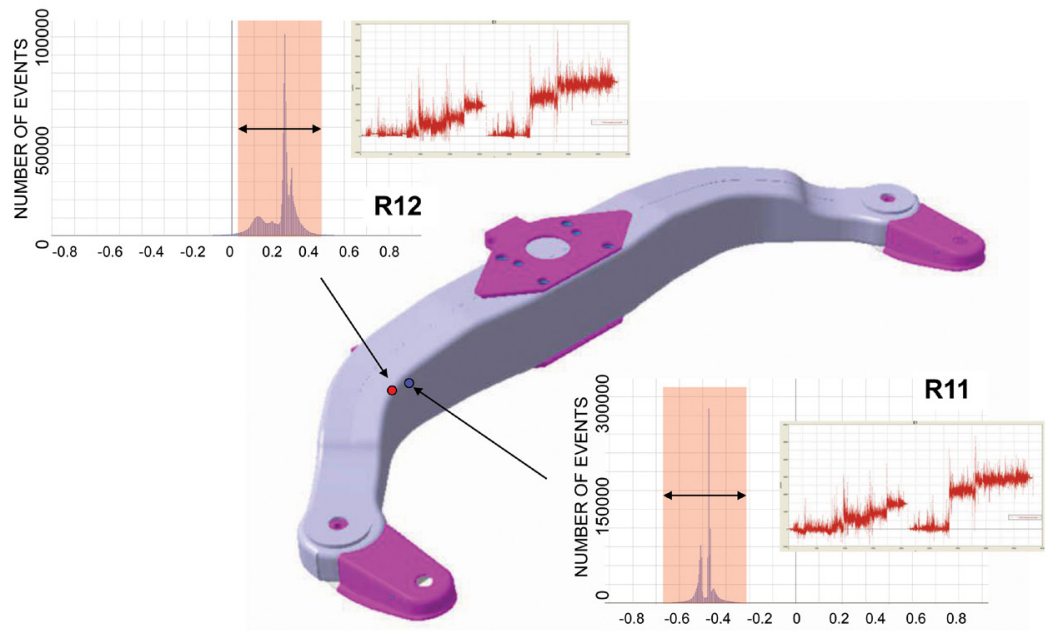

(c) NSC Design

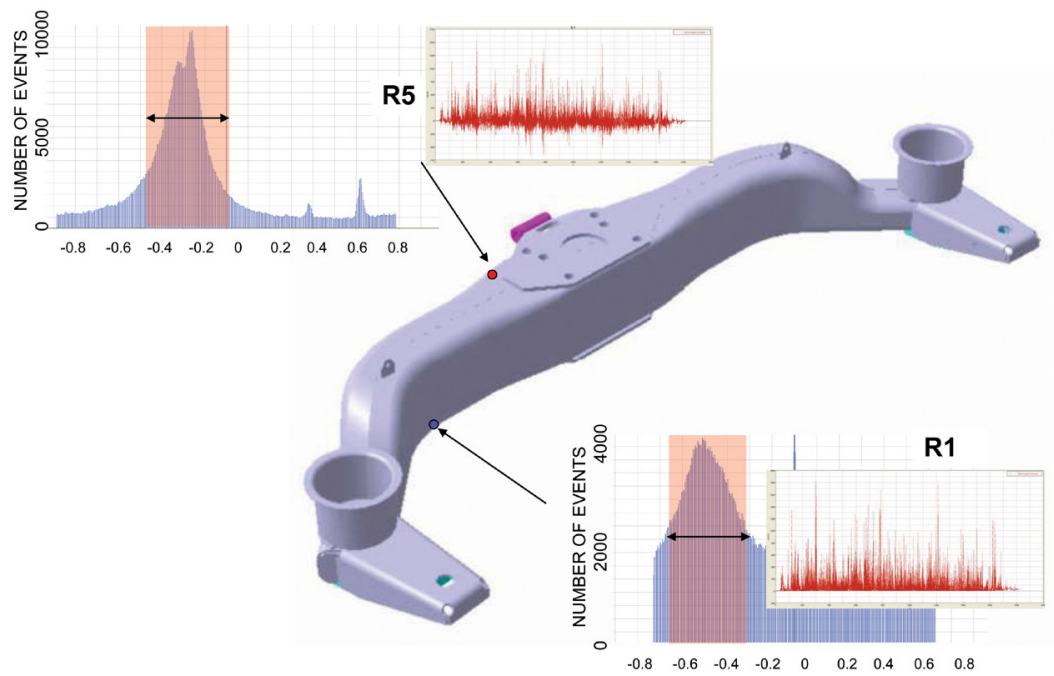

Figure 3. Designs highest measured RMS values signal proportionality. 

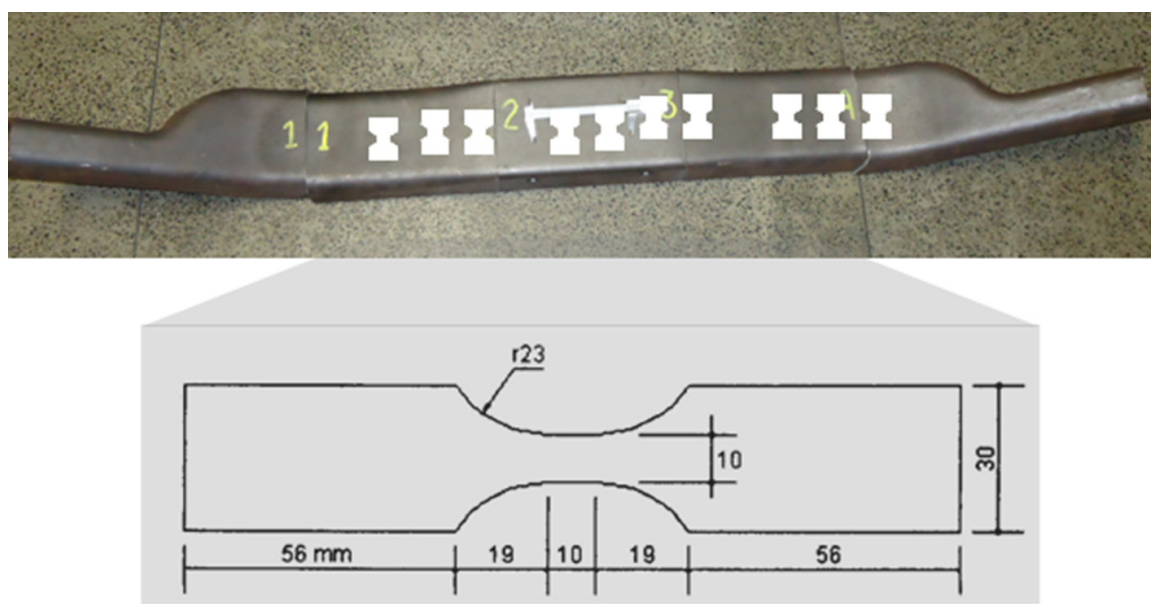

Figure 4. Direction and size $[\mathrm{mm}]$ of the specimens from manufactured parts.

Table 1. Material fatigue data for the used steels.

\begin{tabular}{|c|c|c|c|c|c|c|c|}
\hline Material & n' & $\mathbf{K}^{\prime}$ & b & $\sigma^{\prime} \mathbf{f}(\mathbf{M P a})$ & $\varepsilon^{\prime} \mathbf{f}$ & c & E [Mpa] \\
\hline E380TM & 0,0754 & 588 & $-0,0695$ & 702 & 0,269 & $-0,5653$ & 189000 \\
\hline St52 & 0,1737 & 812 & $-0,1132$ & 827 & 0,31 & $-0,5335$ & 210000 \\
\hline LNE700 & 0,0872 & 799 & $-0,085$ & 967 & 2,27 & $-0,8$ & 195000 \\
\hline
\end{tabular}

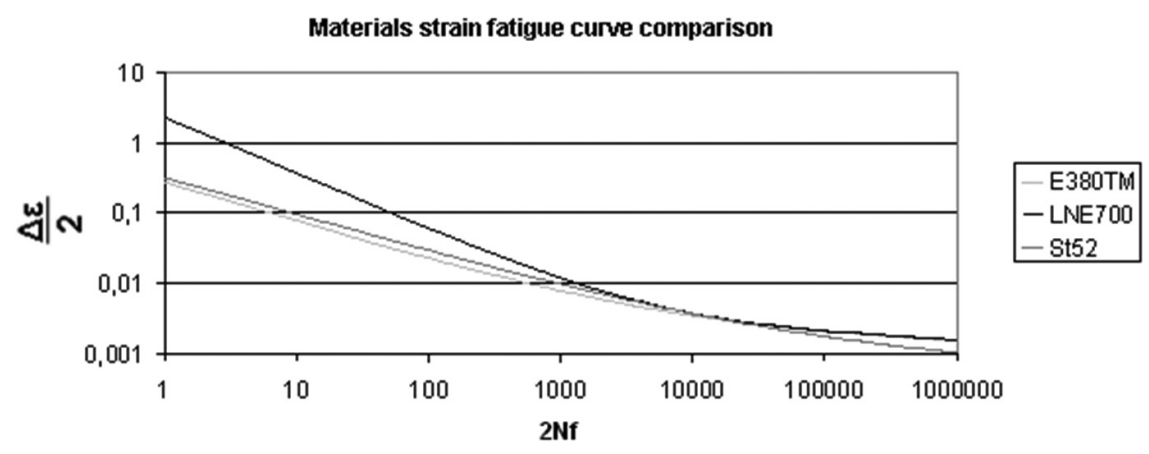

Figure 5. Designs materials Strain-Life Fatigue curves.

$\frac{\Delta \varepsilon}{2}=\frac{\sigma_{f}^{\prime}}{E}\left(2 N_{f}\right)^{b}+\sigma_{f}^{\prime}\left(2 N_{f}\right)^{c}$

\section{Local Strain Fatigue and Equivalent Signal}

At this stage, all strain time-history and materials properties are available for conducting a fatigue damage analysis. Considering the time-history data proportional, the bi-axial fatigue from Brown-Miller suggested equation can be solved without requiring the critical plane approach, what simplifies the analysis reducing engineering and computational efforts.

The measured time-history was transformed in terms of principal strain as input for a modified Brown-Miller (Equation 3), recommended for ductile materials.

$$
\frac{\Delta \gamma_{\max }}{2}+\frac{\Delta \sigma_{N}}{2}=1.65 \frac{\sigma_{f}^{\prime}}{E}\left(2 N_{f}\right)^{b}+1.75 \sigma_{f}^{\prime}\left(2 N_{f}\right)^{c}
$$

$\frac{\Delta \varepsilon_{1}}{2}=\frac{\sigma_{f}^{\prime}}{E}\left(2 N_{f}\right)^{b}+\varepsilon_{f}^{\prime}\left(2 N_{f}\right)^{c}$

When multiplying the Equation 4 by a factor of 1.7 an approximated Brown-Miller equation is created in terms of the principal strain data as shown in Equation 5.

$1,7 \frac{\Delta \varepsilon_{1}}{2} \cong 1,65 \frac{\sigma_{f}^{\prime}}{E}\left(2 N_{f}\right)^{b}+1,75 \varepsilon_{f}^{\prime}\left(2 N_{f}\right)^{c}$

In order to consider the mean stress effect on the fatigue damage, the Morrow correction ${ }^{15}$ was adopted, as it is more indicated for steels while the Smith-Watson-Topper would be more indicated for castings and aluminum ${ }^{3,16}$. The final Equation 6 is to be used for the proposed method.

$1,7 \frac{\Delta \varepsilon_{1}}{2} \approx 1,65 \frac{\sigma_{f}^{\prime}-\sigma_{m}}{E}\left(2 N_{f}\right)^{b}+1,75 \varepsilon_{f}^{\prime}\left(2 N_{f}\right)^{c}$ 
Another important model extensively used is the Ramber-Osgood Equation 7 that is applied for finding the $\sigma_{\mathrm{m}}{ }^{17}$ and later to transform the strain into stress using the cyclic fatigue material data found for the components steel.

$\frac{\Delta \varepsilon}{2}=\frac{\Delta \varepsilon_{e}}{2}+\frac{\Delta \varepsilon_{p}}{2}=\frac{\Delta \sigma}{2 E}+\left(\frac{\Delta \sigma}{2 K^{\prime}}\right)^{1 / n^{\prime}}$

The fatigue damage calculation was conducted with the aid of a VBA (Visual Basic Algorithm) routine written matching the algorithm presented in Figure $6{ }^{17}$. First the rosette data is manipulated for principal strains output, followed by classical peak and valley extraction for reducing computational efforts. The simplified principal strains are than submitted to a rainflow cycle counting according to the ASTM E1049 0 85-R97 standard ${ }^{18}$. Materials fatigue data are inputted in the program. Damage for the input signal is calculated using the Palmgren-Miner cumulative damage method.

The results for the three design and correspondent materials are tabulated on Table 2 as function of the number of laps expected to be accomplished before fatigue failure.
The on-road approval criteria is 3000 laps without failure. Therefore, both SSC design and NSC design would be approved, while the LSC design would be reproved for the required application.

The results correlates with the latest vehicle test data. The reference SSC design demonstrated no failure after accomplishing the approval criteria over five different vehicle test, while failure took place on the LSC design after 929 running laps, as shown in Figure 7. The fracture occurred exactly on the position forecasted by the FEM analysis and where the strain-life calculation presented the highest damage result.

Table 2. Fatigue calculation life results for the three designs as number of laps to fail.

\begin{tabular}{lccc}
\hline & ST52 & E380TM & LNE700 \\
\cline { 2 - 4 } & $\varepsilon-\mathrm{N}$ & $\varepsilon-\mathrm{N}$ & $\varepsilon-\mathrm{N}$ \\
\hline LSC design & & & \\
SSC design & & 43103 & \\
NSC design & & & 48402 \\
\hline
\end{tabular}

INPUT DATA

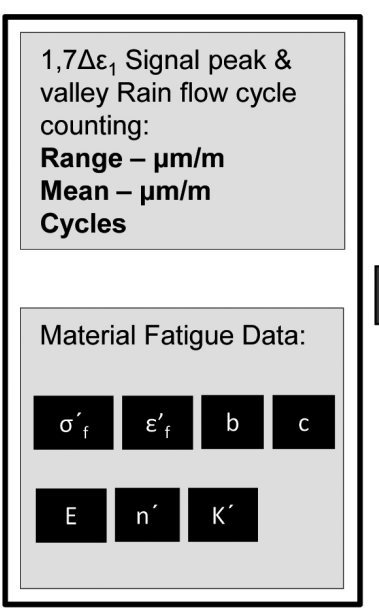

ANALYSIS

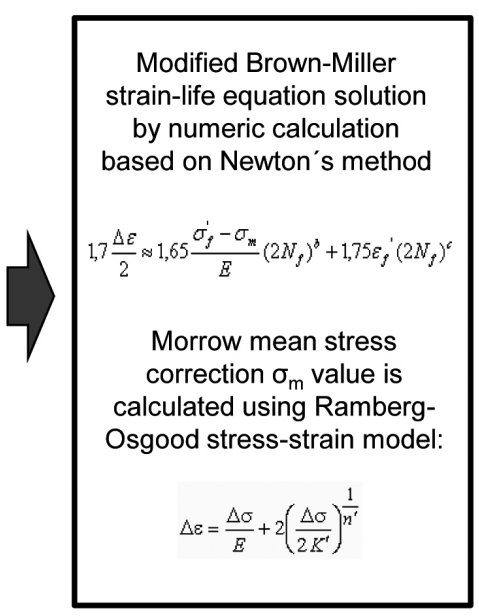

OUTPUT

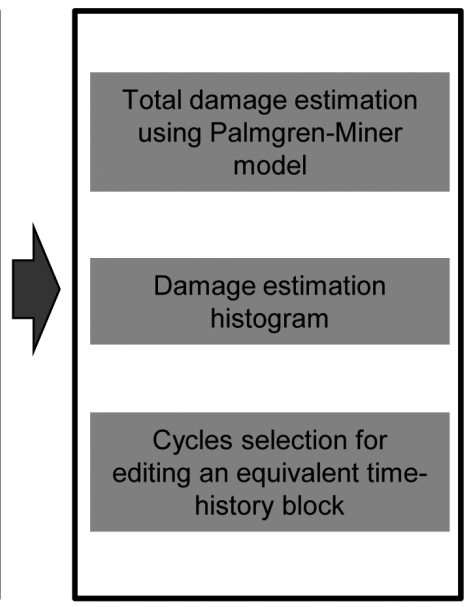

Figure 6. Program algorithm for VBA implementation.


LSC design fatigue fracture in the secondary curve

929 Test Laps

Figure 7. Fatigue failure event during the standard durability track testing program. 

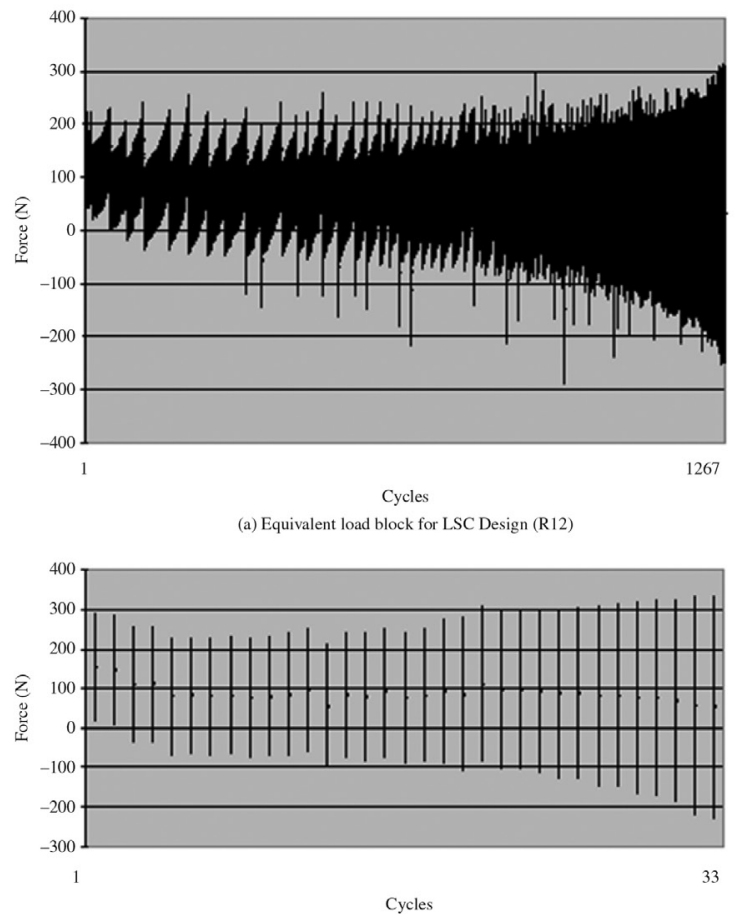

(b) Equivalent load block for SSC design (R12)

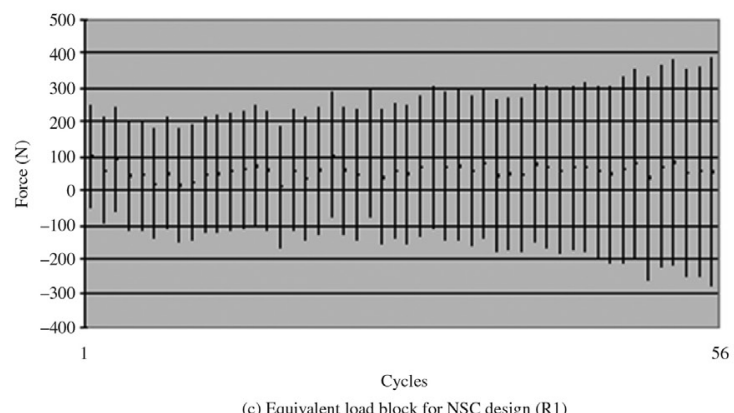

Figure 8. Equivalent load blocks for the three designs fatigue spectra.
The method and modeling demonstrated high confidence for editing equivalent signals considering the rainflow cycles that resulted in high damage to the material. By separating these cycles, all other cycles that do not influence fatigue are dismissed. The proposed editing method is highly dependent on the material properties as it uses the fatigue damage model from Equation 5 and Equation 6 from RambergOsgood for strain - stress transformation.

\section{Testing Program and Reliability Analysis}

Wöhler considered that engineers must have the knowledge of the loads in order to design against fatigue ${ }^{19}$. Therefore load control is the simplest way to check for fatigue performance on a real test as it does not have to account the non-linearity from the material curves, as well as it can be cycled in much higher frequency compared to a strain controlled test program.

The input data for the edited equivalent damage load signals are plotted in Figure 8. It shows a smaller load input signal for designs 1 and 3. For the LSC design, as it suffers damage from a bigger rainflow cycle matrix, the force input signal required resulted to be longer.

At least seven specimens from each components materials were submitted to the uniaxial equivalent load time-history in a standard fatigue test device as shown in Figure 9. The testing frequency reached up to $50 \mathrm{~Hz}$ what enabled to gather the durability cycles results quite fast.

The results for all specimens were saved and organized on Table 3 as function of the number of laps from the standard testing track, where one equivalent signal block represents two times the time history of one lap.

Since the results are different for each specimen, Weibull distribution is used as preference for probability fatigue failure analysis ${ }^{14}$. The $\mathrm{B}_{10}$ life is an expected value corresponding to a failure rate of $10 \%$ which is used to guide engineers for decision. Ranking the experimental data it is possible to find the Weibull parameters for each experiment and plot them all in a diagram presented on Figure 10.

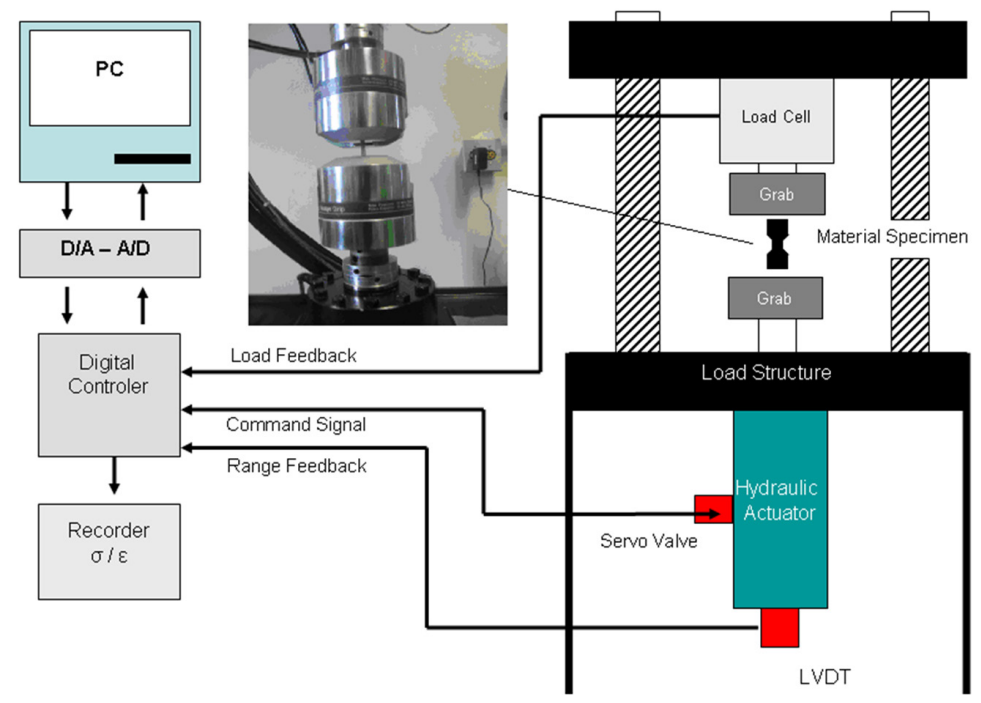

Figure 9. Uni-axial fatigue testing equipment. 
Table 3. Experimental life results for the designs materials specimens as equivalent laps.

\begin{tabular}{cccccc}
\hline \multicolumn{2}{c}{ LSC design } & \multicolumn{2}{c}{ SSC design } & \multicolumn{2}{c}{ NSC design } \\
\hline Sample & Equivalent Laps & Sample & Equivalent Laps & Sample & Equivalent Laps \\
\hline BI1 - T & 1748 & BN1 - T & 26250 & BG1 - T & 43004 \\
BI2 - T & 1212 & BN2 - T & 31534 & BG2 - T & 19388 \\
BI3 - T & 1212 & BN3 - T & 23156 & BG3 - T & 19912 \\
BI4 - T & 1484 & BN4 - T & 21382 & BG4 - T & 32102 \\
BI5 - T & 1214 & BN5 - T & 15378 & BG5 - T & 31308 \\
BI6 - T & 1108 & BN6 - T & 18488 & BG6 - T & 93190 \\
BI7 - T & 946 & BN7 - T & 43180 & BG7 - T & 79230 \\
\hline
\end{tabular}

Weibull curves for the tests results

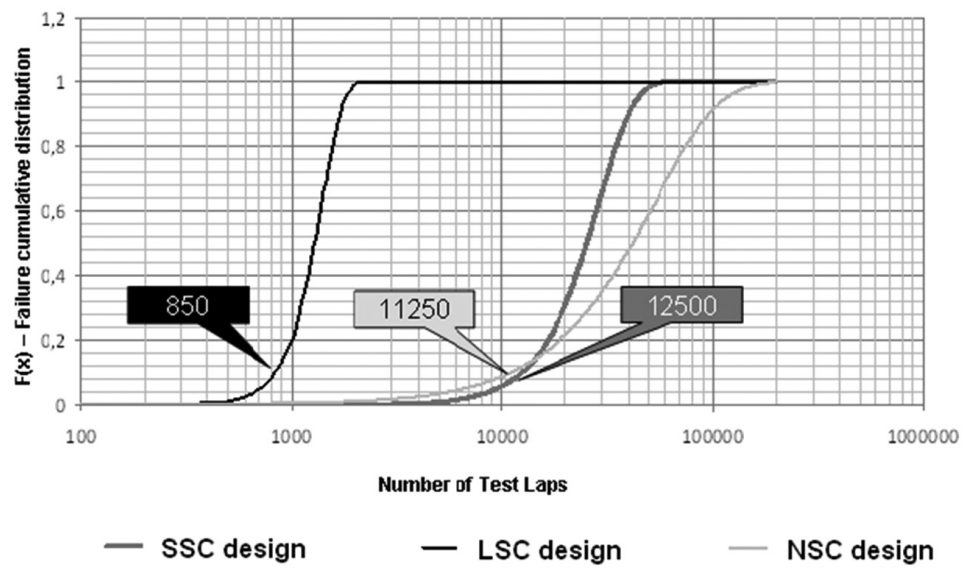

Figure 10. Weibull curves showing the expected B10 life for each design.

The $\mathrm{B}_{10}$ life for LSC design presents good correlation comparing with the reported failure laps from Figure 7 and the fatigue damage calculation prediction from Table 2. The SSC and NSC designs presented more conservative results in respect to the fatigue damage calculation from Table 2. Nevertheless, considering the approval criteria of 3000 laps, the testing results demonstrated a positive no-failure experience for the SSC design, that can be used as benchmark to structurally release the NSC design for series production. The close relationship from the experimental and theoretical life results validated the method for further applications.

\section{Conclusion}

The method presented a successful systematic approach for fatigue life assessment for steel components considering the most available engineering tools used for product development in structural field. From digital to experimental procedures it was possible to set the maturity level for the NSC design allowing early stage decision making considering tooling investments release and design homologation for production. This structural approach is a differential to be extensively applied and further enhanced for product development processes within a high pressure time to market environment.

The fatigue calculations using Brown-Miller equation model for a bi-axial stress field correlates with the structural data from the two reference designs subjected to the same load conditions validating the model for predicting life during design phase.

The calculation procedure for obtaining an edited equivalent uniaxial load collective together with a simplified material fatigue experiment demonstrated also good correlation with the reference fatigue data, thus, validating this technique for future applications during testing phase.

The new development named NSC design has reached the desired fatigue life compared to the successful SSC design. It was released for serial production with high confidence avoiding time consuming on-road durability tests and high costs test bench program procedures. 


\section{References}

1. Chu CC. Multiaxial fatigue life prediction method in the ground vehicle industry. International Journal of Fatigue. 1997; 19:325-330. http://dx.doi.org/10.1016/S01421123(97)00018-2

2. Manson SS and Halford GR. Fatigue and durability of structural materials. Ohio: ASM International; 2006.

3. Brown MW and Miller KJ. A theory for fatigue failure under multiaxial stress-strain conditions. Proceedings of Institute of Mechanical Engineers. 1973; 187:745-755.

4. Draper J. Modern metal fatigue analysis. EMAS; 2008.

5. Fatemi A and Shamsaei N. Multiaxial Fatigue: An overview and some approximation models for life estimation. International Journal of Fatigue. 2011; 33:948-978. http:// dx.doi.org/10.1016/j.ijfatigue.2011.01.003

6. Macha E and Nieslony A. Critical plane fatigue life models of materials and structures under multiaxial stationary random loading: The state-of-the-art in Opole Research Centre CESTI and directions of future activities. International Journal of Fatigue. 2012;. 39:95-102. http://dx.doi.org/10.1016/j. ijfatigue.2011.03.001

7. Conle FA and Chu CC. Fatigue analysis and the local stress-strain approach in complex vehicular structures. International Journal of Fatigue. 1997; 19:317-323. http:// dx.doi.org/10.1016/S0142-1123(97)00045-5

8. Narderi $\mathrm{M}$ et al. Analysis of microstructure and mechanical properties of different high strength carbon steels after hot stamping. Journal of Materials Processing Technology. 2011;211:1117-1125. http://dx.doi.org/10.1016/j. jmatprotec.2011.01.015

9. Heuler P and Seeger T. A criterion for omission of variable amplitude loading histories. International Journal of
Fatigue. 1986; 8: 225-230. http://dx.doi.org/10.1016/01421123(86)90025-3

10. Grubisic V. Determination of load spectra for design and testing. International Journal of Vehicle Design. 1986; 8(4):225-230.

11. Smith KN, Watson P and Topper TH. A Stress-Strain Function for the Fatigue of Metals. Journal of Materials, ASTM. 1970; 5(4):767-778.

12. Stephens RI, Dindingert PM and Gunger JE. Fatigue damage editing for accelerated durability testing using strain range and SWT parameter criteria. International Journal of Fatigue. 1997; 19:599-606. http://dx.doi.org/10.1016/S01421123(97)00079-0

13. American Society for Testing and Materials. ASTM Designation E606-04: Standard Practice for Strain-Controlled Fatigue Testing. ASTM International; 2004.

14. Stephens RI et al. Metal Fatigue in Engineering. New York. John Wiley \& Sons; 2001.

15. Morrow JD. Fatigue Design Handbook. SAE Advances in Engineering. 1968; 4:21-29.

16. Dowling NE. Mechanical Behavior of Materials, 3rd edition. Englewood Cliffs: Prentice Hall; 2007.

17. Spinelli DM. Metodologia enxuta para desenvolvimento de componentes estruturais, suportada por ferramentas de projeto, processo de manufatura e ensaios de materiais [Thesis]. São Carlos: Universidade de São Paulo; 2012.

18. American Society for Testing and Materials. ASTM Designation E1049 85 - R97: Standard Practice for Cycle Counting in Fatigue Analysis. ASTM International; 1997.

19. Schütz W. A history of fatigue. Engineering Fracture Mechanics. 1996; 54(2):263-300. http://dx.doi.org/10.1016/00137944(95)00178-6

Appendix. List of simbols.

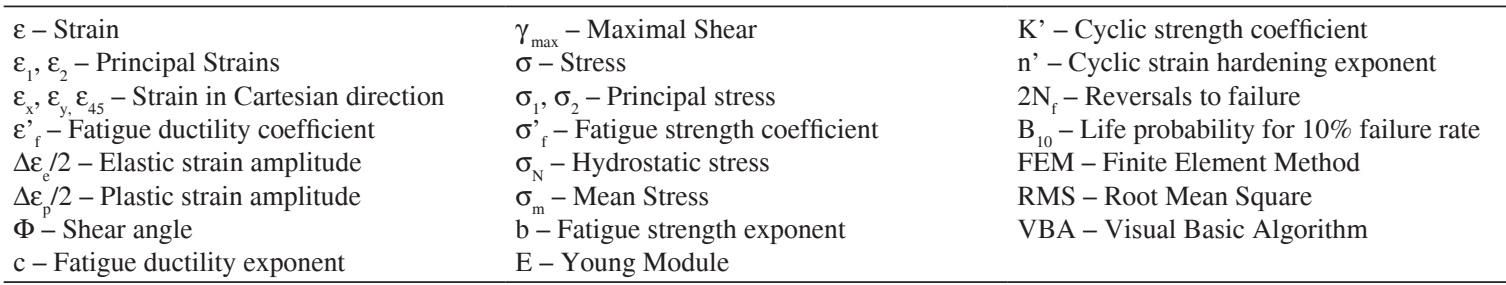

